\title{
Morphological changes in electrochemically deposited poly(3,4- ethylenedioxythiophene) films during overoxidation
}

\author{
M. Ujvária , J. Gubicza ${ }^{\mathrm{b}}$, V. Kondratiev ${ }^{\mathrm{c}}$, K.J. Szekeres ${ }^{\mathrm{a}}$, G.G. Lánga, \\ ${ }^{a}$ Institute of Chemistry, Laboratory of Electrochemistry and Electroanalytical Chemistry, ${ }^{b}$ Institute of Physics, \\ Department of Materials Physics, Eötvös Loránd University, Pázmány P. s. 1/A, H-1117 Budapest, Hungary, \\ ${ }^{c}$ Chemical Department, St. Petersburg State University, Universitetskii pr. 26, 198504, Russia
}

\begin{abstract}
Electrochemical and morphological properties of thin poly(3,4-ethylenedioxythiophene) (PEDOT) films deposited on gold were investigated in aqueous sulfuric acid solutions. X-ray diffraction and electron microscopy were used for monitoring the morphological changes and structure evolution caused by overoxidation. The diffraction peaks of PEDOT became sharper and more intensive during the subsequent oxidation cycles. This indicates that besides the degradation of the PEDOT film its crystallinity was gradually improved with increasing the number of oxidation cycles. These changes may result in the appearance of novel properties that may be advantageous for specific applications.
\end{abstract}

Keywords: overoxidation of PEDOT; crystalline phase; scanning electron microscopy; X-ray diffraction; sensors;

\section{Introduction}

Conductive polymers are used in a variety of applications that require materials which are both electrically conducting and mechanically compliant. Electronic and electrochemical devices based on organic materials are e.g. light emitting diodes, organic thin film transistors, solar cells, memory devices, ion-selective electrodes, microelectrode arrays, fuel cells, etc. [115]. Beyond doubt the monitoring of the degradation of the polymer layers is of great importance for the long term use of these devices.

Among the organic conducting polymers poly(3,4-ethylenedioxythiophene) [16], often abbreviated as PEDOT, and its derivatives appear to be among the most stable organic conducting polymers currently available. Previous studies have shown that PEDOT is highly 
insoluble in almost every solvents, it is electroactive in aqueous solutions [17-19], and exhibits a relatively high conductivity. On the basis of these results studies have been performed to investigate the electrochemistry of PEDOT in more detail e.g. by using cyclic voltammetry (CV). It has been found in refs. [20-22] that when the positive potential limit of the CV is extended into the region in which the overoxidation of the polymer film takes place, an oxidation peak (without a corresponding reduction peak) appears, but only minor changes can be observed in the properties of the cyclic voltammograms recorded in the "stability region" before and after overoxidation.

In Refs. [16] and [22], it has been shown that PEDOT films deposited on $\mathrm{Au}$ or Pt undergo structural changes during the overoxidation (degradation) process. The most probable stages involved in the overoxidation/delamination process are: i) Overoxidation results in stress generation in the PEDOT film [23]. ii) Formation of cracks due to internal stress. iii) The residual products of the degradation of the polymer leave the polymer layer. iv) After the formation of the line cracks, the film stress is partially released. v) The partial delamination of the polymer layer leads to exposure of the underlying metal substrate to the electrolyte solution. vi) The polymer film still present on the substrate after overoxidation remains electroactive. vii) The areas with the polymer form a barrier between the metal substrate and the surrounding electrolyte solution.

Although the above conclusions seem to be justified, the internal structure of the polymer film remaining on the substrate after the overoxidation process has not been investigated in the papers mentioned above. This topic may, however, be an interesting subject for further studies, since according to literature reports conducting polymers in different overoxidation states show unique features useful for analytical, sensing and biomedical applications [24-27].

For instance, many studies have demonstrated that overoxidized polypyrrole films exhibit molecular-sieve properties, and such films have been used to fabricate glucose, alcohol, hydrazine, and dopamine sensors [25-32]. A demonstration of an organic electronic ion pump containing parts made of overoxidized PEDOT:PSS (Poly(3,4ethylenedioxythiophene):poly(styrenesulfonate)) was provided in Refs.[27,33]. In [34] oxidized PEDOT films were successfully used for sensing perchlorate. It is also well known that in conductive polymer based ion bipolar junction transistors emitter and collector are cation selective and contain overoxidized PEDOT [35,36]. According to [37] an overoxidized poly(3,4-ethylenedioxythiophene) film-modified screen-printed carbon electrodes exhibited superior sensitivity and selectivity for the recognition of electrochemical probes, leading to the 
determination of submicromolar concentration of dopamine without interference from the existing 10 times of concentration of uric acid and 1000 times of concentration of ascorbic acid. The basis for the observed selectivity of overoxidized polymer films is not entirely clear. In some cases it is attributed to the increase in porosity of the polymer film [32,38].

The purpose of the present paper is to complement (and extend) the results reported in [21] and [22] by studying the morphological changes in electrodeposited PEDOT films during overoxidation. As it has been pointed out in [22] the overoxidation/degradation of PEDOT films can result in random-like, but quite well-ordered arrays of islands and trench-like structures. This may imply an increase of the crystalline fraction in the polymer layer. In the present work, we tried to check this assumption. In order to gain a deeper insight into these issues X-ray diffraction along with electron microscopy were used for monitoring the structure evolution of the films during the overoxidation process.

\section{Experimental}

\subsection{Solutions and film preparation}

The gold/poly(3,4-ethylenedioxythiophene) films were prepared by electropolymerization from $0.01 \mathrm{~mol} \cdot \mathrm{dm}^{-3}$ ethylenedioxythiophene (EDOT) $/ 0.1 \mathrm{~mol} \cdot \mathrm{dm}^{-3} \mathrm{Na}_{2} \mathrm{SO}_{4}$ solution under galvanostatic conditions. The PEDOT films were formed on gold plates or on gold layers deposited by vacuum evaporation onto glass substrates. A constant current density of $0.2 \mathrm{~mA} \cdot \mathrm{cm}^{-2}$ was applied for $7200 \mathrm{~s}$. Analytical grade 3,4-ethylenedioxythiophene (Aldrich), p.a. $\mathrm{Na}_{2} \mathrm{SO}_{4}$ (Fluka), and ultra-pure water (specific resistance $18.3 \mathrm{M} \Omega \cdot \mathrm{cm}$ ) were used for solution preparation. The $0.1 \mathrm{M} \mathrm{H}_{2} \mathrm{SO}_{4}$ solutions used for voltammetric experiments were prepared with ultra-pure water, and p.a. $\mathrm{H}_{2} \mathrm{SO}_{4}$ (Merck). All solutions were purged with oxygen-free argon (Linde 5.0) before use and an inert gas blanket was maintained throughout the experiments.

An Autolab PGSTAT 20 potentiostat was used to control the electrochemical cell operations and data acquisition. The film thickness $(d \approx 2.9 \mu \mathrm{m})$ was estimated from the amount of charge passed in the deposition of the PEDOT film, and by using the charge/film volume ratio determined earlier by direct thickness measurements $[39,40]$. The thickness of the films investigated in the present work was about two times larger than that reported in [21] and [22] since thicker films were required to obtain reliable X-ray diffraction data.

\subsection{Voltammetry}


The conventional three-electrode cell configuration was used. A high surface area goldfoil was arranged cylindrically around the working electrode to maintain a uniform electric field (counter electrode). A NaCl saturated calomel electrode (SSCE) was used as the reference.

\subsection{Scanning Electron Microscopy (SEM)}

The oxidation of the polymer film has been followed with scanning electron microscopy. A Quanta ${ }^{\mathrm{TM}}$ 3D FEG high-resolution, low-vacuum SEM/FIB instrument was used for SEM analysis.

\section{$2.4 X$-ray diffraction $(X R D)$}

The phase composition of PEDOT was studied by X-ray diffraction using a Philips Xpert powder diffractometer with $\mathrm{CuK \alpha}$ radiation (wavelength: $0.15418 \mathrm{~nm}$ ) and BraggBrentano geometry [41].

\section{Results and discussion}

\subsection{Cyclic voltammetry}

In the potential interval $-0.3 \mathrm{~V}-0.8 \mathrm{~V}$ vs. SSCE the PEDOT films are remarkably stable, retaining their properties even after several consecutive cyclic voltammetric scans. The cyclic voltammograms in Fig. 1 have been selected from a series of 40 scans which were recorded in $0.1 \mathrm{M}$ aqueous sulfuric acid solution (scan rate: $v=50 \mathrm{mV} \cdot \mathrm{s}^{-1}$ ) immediately after the first XRD measurement performed on the freshly made film (see curve 1 in Fig.6, geometric surface area of the film: $4.0 \mathrm{~cm}^{2}$ ). As it can be seen from the figure, the oxidation-reduction process is reversible, if the positive electrode potential limit is kept below $0.8 \mathrm{~V}$ vs. SSCE. Except for the first scan, the capacitances at the corresponding electrode potentials remained almost unchanged with the increasing number of potential cycles. A similar conclusion is true for the X-ray powder diffractograms taken before and after the potential cycling treatment: patterns characteristic for an amorphous state have been identified in the sample in both cases (see Fig.6, curves 1 and 2).

Cyclic voltammetric curves recorded for the gold |PEDOT $\mid 0.1 \mathrm{M}$ sulfuric acid (aq) electrode (geometric surface area: $4.0 \mathrm{~cm}^{2}$ ) at a sweep rate of $v=50 \mathrm{mV} \cdot \mathrm{s}^{-1}$ are presented in Fig.2b. The potential program applied to the electrode is given in Fig.2a. Three time intervals in Fig.2a are marked by "A", "B", and "C". According to the results, irreversible oxidation of the PEDOT film starts at or above $0.8 \mathrm{~V}$ vs. SSCE. The shapes of the cyclic voltammograms change considerably if the electrode potential exceeds this value ("overoxidation cycles": see 
e.g. curves 2,4,6 in Fig.2b), an oxidation peak with no corresponding reduction peak can be observed at potentials above $0.8 \mathrm{~V}$. By comparing e.g. curve 1 and curve 3 in Fig. $2 \mathrm{~b}$, it can be seen that there are only small differences between the voltammograms recorded in the $0.3 \mathrm{~V}-0.8 \mathrm{~V}$ potential range before and after three "overoxidation cycles" taken between $0.3 \mathrm{~V}$ and $1.2 \mathrm{~V}$. However, if the positive limit of the electrode potential is extended to $1.5 \mathrm{~V}$ vs. SSCE, the intensity of the redox response (i.e. the capacitance of the film) gradually decreased (see curves 3, 5 and 7 in Fig.2b). Nevertheless, curve 7 still shows the presence of a significant amount of polymer in direct (electrical) contact with the gold surface.

\subsection{SEM micrographs of the PEDOT layers on Au}

The SEM images of the PEDOT film prepared freshly on gold are presented in Fig.3a. One can see in the image detected by secondary electrons (SE), that well-separated globules (or cauliflower-like particles) are present on the top of the polymer layer. The backscattered electron (BSE) micrograph taken from the same area (which characterizes a thicker layer compared to SE) shows that the globules are attached to an underlying smoother polymer layer (Fig.3b).

Figs.4a and $4 \mathrm{~b}$ show SEM images of the PEDOT film prepared on gold after the application of 40 potential cycles $(\mathrm{CV}-\mathrm{s})$ at $50 \mathrm{mVs}^{-1}$ in the range from $-0.3 \mathrm{~V}$ to $0.8 \mathrm{~V}$ vs. SCE. The most striking difference between the micrograph shown in Fig.4a and that of the freshly prepared sample in Fig.3a is the appearance of some narrow cracks or crevices in the SEM image of the oxidized film. The cracks results in bright spots ("islands") in the backscattered SEM images (Fig.4b). The formation of the cracks can be well explained as the result of internal stress changes in the thick polymer film [21-23].

Figs.5a and 5b show SE and BSE SEM images, respectively, for the PEDOT film after the time interval " $\mathrm{C}$ " in Fig.2a. The most striking difference between the micrograph shown in Fig.5a and that of the freshly prepared sample in Fig.3a is the appearance of a network of grooves (narrow trench-like structures). The width of the crevices shown in Figs.5a is about 2$3 \mu \mathrm{m}$. According to the backscattered SEM micrographs (Fig.5b) the crevices are interconnected and form a widespread network. EDX analysis proved, that only Au is present at the bottom of the grooves.

\section{$3.3 X$-ray diffraction}

The powder diffractograms obtained for the initial state (curve 1), after 40 consecutive cyclic voltammetric scans in the potential interval $-0.3 \mathrm{~V}-0.8 \mathrm{~V}$ vs. SSCE (curve 2), and after 
the time intervals "A", "B" and "C" specified in Fig.2a are shown in Fig.6 (curves A,B and C). Partial crystallinity with well-separated X-ray diffraction peaks is observed in the overoxidized PEDOT film (curves A, B and C) while a pattern characteristic for an amorphous state is identified in the samples without overoxidation (curves 1 and 2). This proves directly that the crystallization is the result of overoxidation and not of the potential cycling alone.

The diffraction peaks of crystalline PEDOT were indexed according to previous studies $[42,43]$. These works identified this phase as orthorhombic structure. The best agreement between the theoretical orthorhombic and the experimental peak positions was obtained by selecting the following values for the three lattice parameters: $a=0.980 \mathrm{~nm}, b=0.690 \mathrm{~nm}$, $c=0.405 \mathrm{~nm}$. The value of $b$ is very close to the lattice constant $(b=0.679 \mathrm{~nm})$ determined from reflection 020 in a previous study [43]. However, it should be noted that the values of the lattice parameters of PEDOT are very sensitive on the type of counter ion as revealed in Table 2.1 of Ref. [43]. Fig. 6 shows that the diffraction peaks of PEDOT became sharper and more intensive due to electrochemical treatment (curves A,B and C). This indicates that besides the degradation of the PEDOT film its crystallinity was gradually improved with increasing the number of oxidation cycles.

\section{Conclusions}

According to the above experimental results the originally compact and strongly adherent PEDOT films undergo structural changes during over oxidation. The porosity of the film increases progressively during the degradation process. X-ray diffraction results showed that besides degradation, the crystallinity of the PEDOT film was also gradually improved with increasing number of overoxidation cycles. These changes may result in the generation of sites with novel catalytic and binding properties that may be advantageous for specific applications.

\section{Acknowledgements}

Financial support from the Hungarian Scientific Research Fund (grants No. K 109021 and K 109036) and from the Russian Foundation for Basic Research (grant N-13-03-00984) are gratefully acknowledged. The authors thank Prof. K. Havancsák and Prof. G. Varga for the SEM measurements, and for helpful discussions: The project was supported by the European Union and co-financed by the European Social Fund (grant agreement no. TAMOP 4.2.1/B09/1/KMR-2010-0003). 
Figure captions

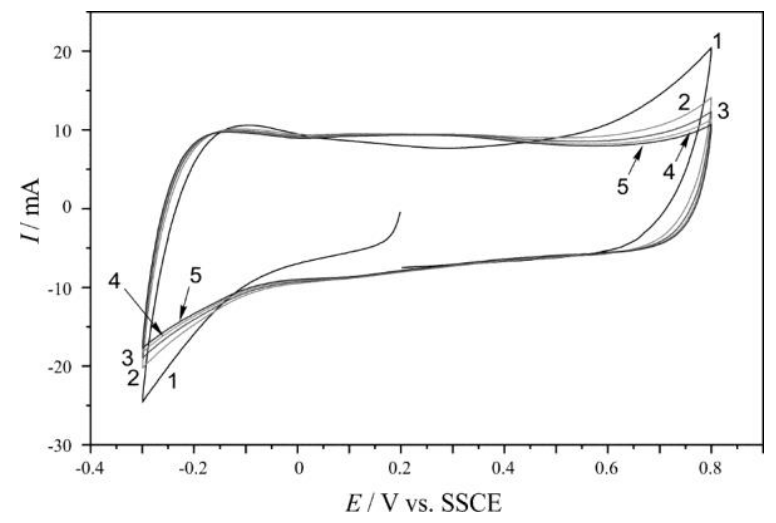

Fig. 1

The cyclic voltammograms recorded in $0.1 \mathrm{M}$ aqueous solution of $\mathrm{H}_{2} \mathrm{SO}_{4}$ (scan rate: $v=50 \mathrm{mV}$ $\mathrm{s}^{-1}$ ). The curves have been selected from a series of 40 repeated scans recorded immediately after the preparation of the PEDOT film.

1: 1 st scan; 2: $10^{\text {th }}$ scan; 3: $20^{\text {th }}$ scan; $4: 30^{\text {th }}$ scan; $5: 40^{\text {th }}$ scan.

(a)

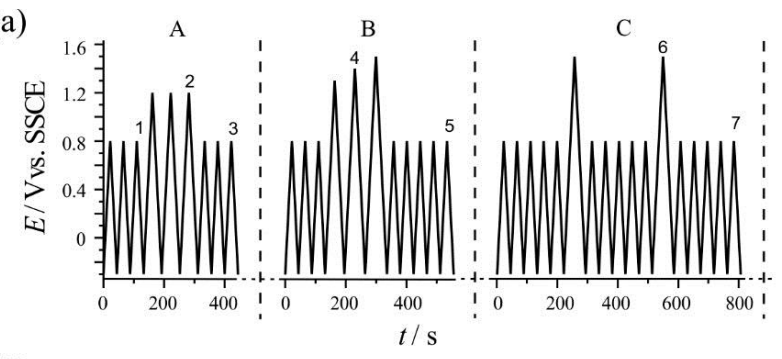

(b)

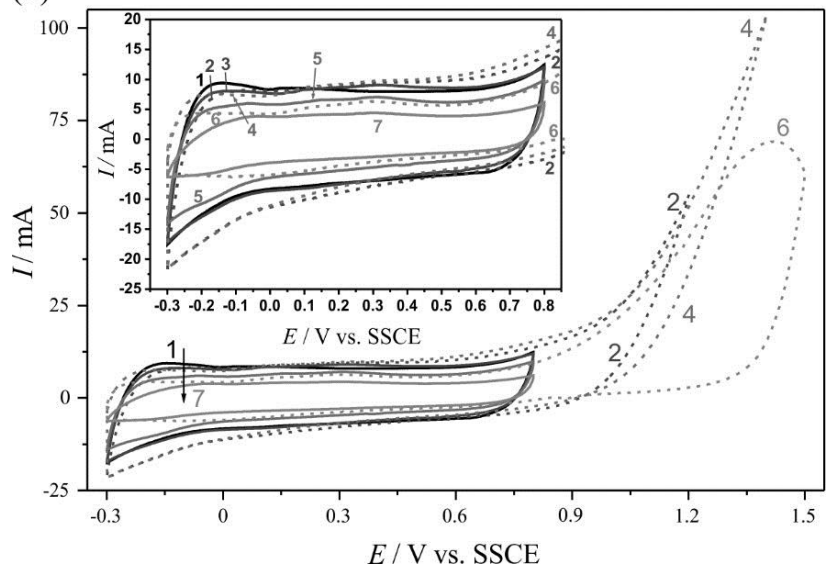


Fig. 2

a: Potential program applied to the Au | PEDOT |0.1 M sulphuric acid electrode. Sweep rates: $v=50 \mathrm{mV} \cdot \mathrm{s}^{-1}$. “A”, "B” and „C" are time intervals, after which XRD patterns presented in Fig.6 were recorded.

b: Cyclic voltammograms corresponding to the cycles marked with 1-7 in "a".

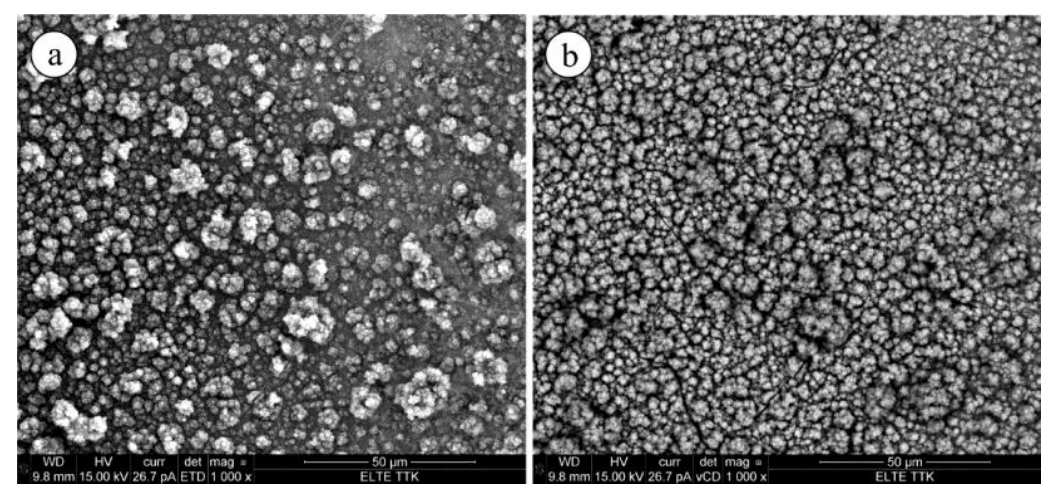

Fig. 3

SEM images of the freshly prepared PEDOT film.

a: SEM image using secondary electrons.

b: the corresponding backscattered SEM image taken from the same area.

The length of the horizontal white bar below the images corresponds to $50 \mu \mathrm{m}$.
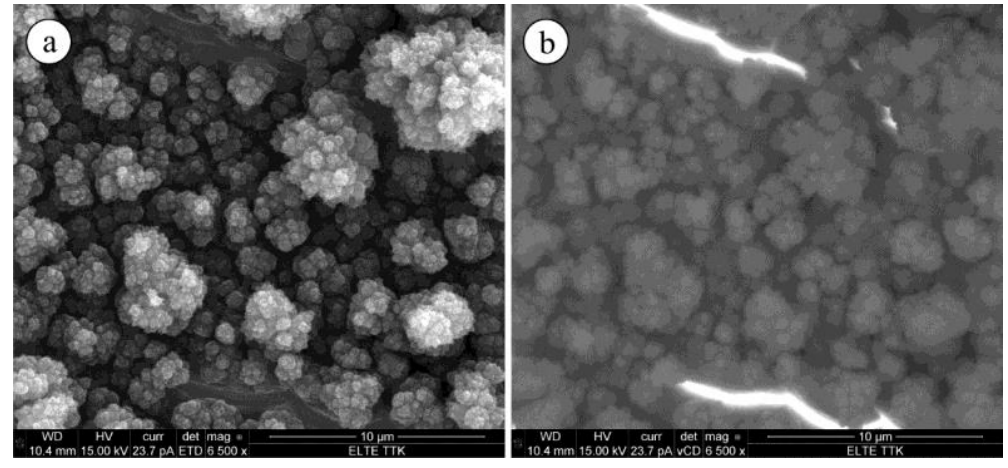

Fig. 4

SEM images of the PEDOT film prepared on gold after the application of 40 potential cycles $\left(v=50 \mathrm{mV} \cdot \mathrm{s}^{-1}\right)$ in the range from $-0.3 \mathrm{~V}$ to $0.8 \mathrm{~V}$ vs. SSCE (see Fig. 1 ).

a: SEM image using secondary electrons.

b: the corresponding backscattered SEM images taken from the same area.

The length of the horizontal white bar below the images corresponds to $10 \mu \mathrm{m}$. 


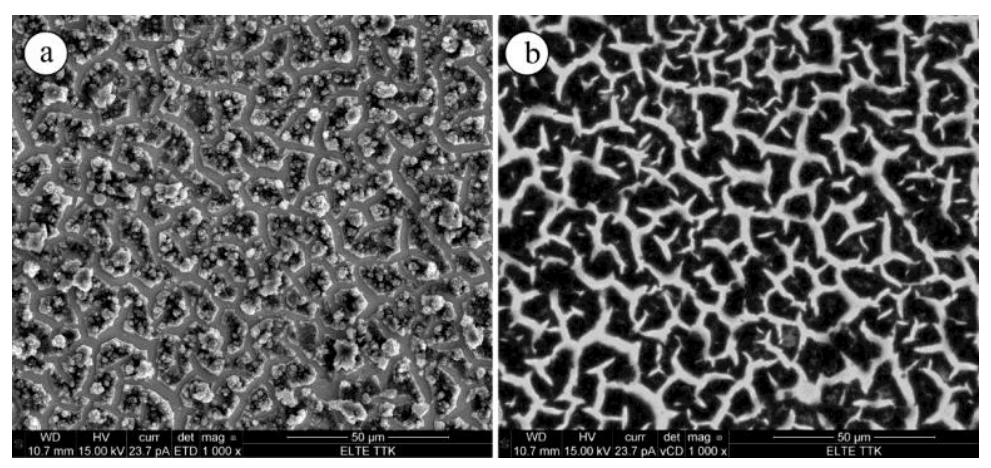

Fig. 5

SEM images of the PEDOT film recorded after time interval "C" in Fig.2a (overoxidized film). a: SEM image using secondary electrons.

b: the corresponding backscattered SEM images taken from the same area.

The length of the horizontal white bar below the images corresponds to $50 \mu \mathrm{m}$.

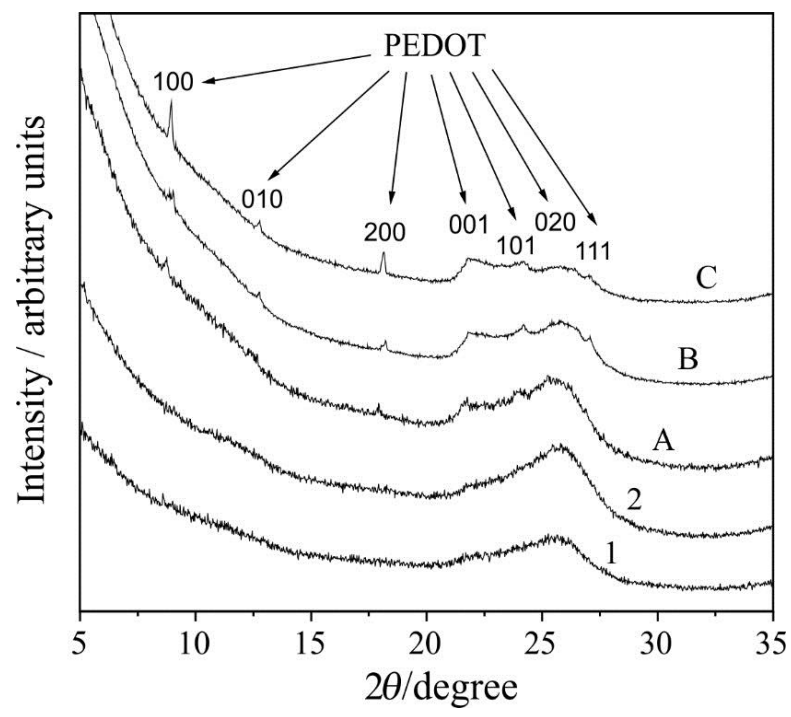

Fig. 6

X-ray diffractograms. 1: freshly prepared PEDOT film; 2: PEDOT film after the application of 40 potential cycles $\left(v=50 \mathrm{mV} \cdot \mathrm{s}^{-1}\right)$ in the range from $-0.3 \mathrm{~V}$ to $0.8 \mathrm{~V}$ vs. SSCE (see Fig.1); A,B,C: obtained after time intervals "A","B" and "C" in Fig.2a, respectively. 


\section{References}

[1] Kvarnström C (2012) Conducting Polymers In: Bard AJ, Inzelt G, Scholz F. (eds) Electrochemical Dictionary, 2nd edn. Springer, Heidelberg

[2] Inzelt G (2012) Conducting polymers. A new era in electrochemistry, 2nd edn. In: Scholz F (ed) Monographs in electrochemistry, Springer, Berlin Heidelberg

[3] Lang U, Naujoks N, Dual J (2009) Synthetic Met 159:473-479

[4] Inzelt G (1994) In: Bard AJ (ed) Electroanalytical chemistry, vol. 18. Marcel Dekker, New York

[5] Wang GF, Tao XM, Wang RX (2008) Nanotechnology 19:145201-145202

[6] Inzelt G, Pineri A, Schultze JW, Vorotyntsev MA (2000) Electrochim. Acta 45:2403-2421

[7] Lilliedal MR, Medford AJ, Madsen MV, Norrman K, Krebs FC (2010) Sol Energ Mat Sol C 94:20182031

[8] Nasybulin E, Wei S, Cox M, Kymissis I, Levon K (2011) J Phys Chem C 115:4307-4314

[9] Scott JC (2004) Science 304:62-63

[10] Möller S, Perlov C, Jackson W, Taussig C, Forrest SR (2003) Nature 426:166-169

[11] Cui X, Martin DC (2003) Sensor Actuat B-Chem 89:92-102

[12] Vázquez M, Danielsson P, Bobacka J, Lewenstam A, Ivaska A (2004) Sensor Actuat B-Chem 97:182189

[13] Bobacka J (1999) Anal Chem 71:4932-4937

[14] Drillet JF, Dittmeyer R, Jüttner K, Li L, Mangold KM (2006) Fuel Cells 6:432-438

[15] Drillet JF, Dittmeyer R, K. Jüttner K (2007) J. Appl. Electrochem. 37: 1219-1226

[16] Kvarnström C (2012) Poly(thiophene) In: Bard AJ, Inzelt G, Scholz F. (eds) Electrochemical Dictionary, 2nd edn. Springer, Heidelberg

[17] Bobacka J, Lewenstam A, Ivaska A (2000) J Electroanal Chem 489:17-27

[18] Yamato H, Ohwa M, Wernet W (1995) J Electroanal Chem 397:163-170

[19] Sakmeche N, Aeiyach S, Aaron JJ, Jouini M, Lacroix JC, Lacaze PC (1999) Langmuir 15:2566-2574

[20] Zykwinska A, Domagala W, Pilawa B, Lapkowski M (2005) Electrochim Acta 50:1625-1633

[21] Ujvári M, Takács M, Vesztergom S, Bazsó F, Ujhelyi F, Láng GG (2011) J Solid State Electrochem $15: 2341-2349$

[22] Láng GG, Ujvári M, Bazsó F, Vesztergom S, Ujhelyi F (2012) Electrochim Acta 73:59-69

[23] Láng GG, Barbero C (2012) Laser techniques for the study of electrode processes, In: Scholz F (ed) Monographs in electrochemistry, Springer, Berlin Heidelberg

[24] Li J, Lin X-Q (2007) Sens Actuators B 124:486-493

[25] Martin DC, Wu J, Shaw CM, King Z, Spanninga SA, Richardson-Burns S, Hendricks J, Yang J (2010) Polym Rev 50:340-384

[26] Zhuang Z, Li J, Xu R, Xiao D (2011) Int J Electrochem Sci 6:2149-2161

[27] Irimia-Vladu M (2014) Chem Soc Rev 43:588-610

[28] Majidi MR, Jouyban A, Asadpour-Zeynali K (2007) Electrochim Acta 52:6248-6253

[29] Tu X, Xie Q, Jiang S, Yao S (2007) Biosens Bioelectron 22:2819-2826

[30] Wen J, Zhou L, Jin L, Cao X, Ye B-C (2009) J Chromatogr B 877:1793-1798 
[31] Li Y, Wang P, Wang L, Lin X (2007) Biosens Bioelectron 22:3120-3125

[32] Boateng A, Iraque F, Brajter-Toth A (2013) Electroanalysis 25:345-355

[33] Simon DT, Kurup S, Larsson KC, Hori R, Tybrandt K, Goiny M, Jager EWH, Berggren M, Canlon B, Richter-Dahlfors A (2009) Nat Mater 8:742-746

[34] Bendikov TA, Harmon TC (2005) Anal Chim Acta 551:30-36

[35] Ranjan N, Reddy AHM (2014) Appl Mech Mater 490/491:123-128

[36] Tybrandt K, Larsson KC, Richter-Dahlfors A, Berggren M (2010) Proc Natl Acad Sci USA 107:99299932

[37] Lin J-M, Su Y-L, Chang W-T, Su W-Y, Cheng S-H (2014) Electrochim Acta 149:65-75

[38] Boateng A, Cohen-Shohet R, Brajter-Toth A (2011) Electrochim Acta 56:7651-7658

[39] Stoyanova A, Tsakova V (2010) J Solid State Electrochem 14:1947-1955

[40] Poppendieck W, Hoffmann KP (2009) In: Vander Sloten J, Verdonck P, Nyssen M, Haueisen J (eds), ECIFMBE 2008, IFCMBE Proceedings 22, Springer-Verlag Berlin, Heidelberg, pp. 2409-2412

[41] Klug HP, Alexander LE (1974) X-ray diffraction procedures for polycrystalline and amorphous materials. John Wiley and Sons, New York

[42] Wu J (2011) Morphology of Poly(3,4-ethylene dioxythiophene) (PEDOT) Thin Films, Crystals, Cubic Phases, Fibers and Tubes, PhD dissertation, The University of Michigan

[43] Takano T, Masunaga H, Fujiwara A, Okuzaki H, Sasaki T (2012) Macromolecules 45:3859-3865 